\title{
The Impact of E-Mind Mapping Strategy and Learning Styles on the Achievement of the Tenth- Grade Students in Biology
}

\author{
Ali Abdul Hadi Al-Omari ${ }^{1, *}$, Belal Ahmed Al-Dhoon ${ }^{2}$ \\ ${ }^{1}$ Department of Education, Yarmouk University, Irbid, Jordan \\ ${ }^{2}$ Al-Koura Directorate of Education, Irbid, Jordan
}

Received August 13, 2020; Revised October 3, 2020; Accepted October 24, 2020

\section{Cite This Paper in the following Citation Styles}

(a): [1] Ali Abdul Hadi Al-Omari, Belal Ahmed Al-Dhoon, "The Impact of E-Mind Mapping Strategy and Learning Styles on the Achievement of the Tenth- Grade Students in Biology," Universal Journal of Educational Research, Vol. 8, No. 12, pp. 6429-6438, 2020. DOI: 10.13189/ujer.2020.081208.

(b): Ali Abdul Hadi Al-Omari, Belal Ahmed Al-Dhoon (2020). The Impact of E-Mind Mapping Strategy and Learning Styles on the Achievement of the Tenth- Grade Students in Biology. Universal Journal of Educational Research, 8(12), 6429-6438. DOI: 10.13189/ujer.2020.081208.

Copyright $(2020$ by authors, all rights reserved. Authors agree that this article remains permanently open access under the terms of the Creative Commons Attribution License 4.0 International License

\begin{abstract}
This study aimed at investigating the effect of using E- mind mapping strategy and learning styles on the achievements of tenth-grade students in biology. To achieve the objectives of the study, a quasi-experimental approach was applied. The study sample was divided into two groups, the control group consisted of (24) students who were taught by using the conventional method, and the experimental group (50) students who were taught by using the E- mind mapping strategy. The researchers applied two instruments which were preferred learning styles (VARK) scale (Visual: V. Auditory: A. Read/Write: R. Kinesthetic: $\mathrm{K}$.), and a multiple-choice achievement test for the unit "Taxonomy and Prokaryotes". The results reveal that there is a significant statistical difference at $(\alpha=0.05)$ in achievement due to instructional strategy in favor of the experimental group, and there are statistically significant differences at $(\alpha=0.05)$ in achievement for the levels of Bloom's Taxonomy (remember, understand and apply) in favor of the experimental group. The results also reveal that there are no statistically significant differences at $(\alpha=0.05)$ between the two groups attributed to the learning style or the interaction between the instructional strategy and the learning styles.
\end{abstract}

Keywords E-Mind-Mapping, Learning Styles, Achievement in Biology

\section{Introduction}

As a matter of fact, when educators aim to evaluate the effectiveness of the educational process or to assess the educational level of learners, they usually have recourse to the assessment of the academic and scientific achievements of students. Improving student achievement in the scientific field is considered to be one of the issues of interest to educators, as the decisive educational decisions will depend on providing the concerned educational bodies with indicators related to the achievement of scientific education outcomes, and identifying the learners' interests and their attitudes towards learning science in the future.

The level of achievement of Jordanian students in science, regrettably, does not meet the ambition, and this is confirmed by the results of the international trends in the study of science and mathematics (Trends of the International Mathematics and Science Studies: TIMSS), and the test of the International Student Assessment Program (Program for International Student Assessment: PISA). Actually, Jordan's results came in the last positions compared to the other participating countries according to the National Center for Human Resources Development [1]. The application of conventional teaching methods which mainly depend on memorizing and recalling [2] is one of the factors that play a critical role in the low level of achievement in science. Hence, researchers and educators have dedicated their efforts to finding new effective 
methods and learner-centered teaching strategies that attain meaningful learning and improve student's achievement in sciences as mentioned in [2-3]. Among the successful efforts in this area is the mind mapping strategy by Tony Buzan [4]. He pointed out that the mind mapping strategy is a powerful graphic technique which provides a universal key to unlock the potential of the brain that focuses on applying mental processes for better memorizing and recalling information. Mind mapping is defined in [4] as a 2D note-taking strategy, which helps create a mind map with all the detailed knowledge on a specific subject. It gets applied in many areas for generating new ideas. It can be supported by using colors and drawings to add more suspense and beauty to stimulate creativity and retaining information

Wakad in [5] defined the mental map as a teaching strategy that the teacher employs to provide clear and organized information to the student to help him in understanding details and organizing his cognitive structure. Students can use this method to summarize information and ideas using colors, graphics, or symbols.

The educational literature has addressed the benefits that can be gained when using mind maps. Mind mapping strategy is one of the modern means that help in speeding up learning, organizing ideas and recalling information properly, as well as effectively integrating the learner into the educational process to enable him to reach the highest levels of concentration [4]. Abu Saidi and Al Balushi in [6] pointed out that using mind mapping strategy increases assimilation and understanding in addition to retention of learning, using constructively the left and right brain-thinking tools, enhancing the positivity of the learner, developing multiple intelligence skills and providinges an opportunity to practice creativity. Moreover, the mental map as seen by Holzman [7] is an effective tool for enhancing achievement, as it helps learners to summarize and memorize rules and equations and studying them effectively [8].

Mind maps can be classified into two main types: conventional mind maps that are designed by using paper and pen, E- mind maps that are created using computer programs such as (Mind Mapper, Mind Manager, Free Mind). E-mind maps have more advantages that make them more effective than conventional maps especially in the learning process as it employs modern technologies in education enabling the learner to create his maps, insert images, colorful drawings, modify, revise, print and share with others. This method helps the learner to form an integrated knowledge structure that qualifies him to deeply explore ideas [9]. When employing this strategy in teaching, it provides an opportunity for students to practice analyzing knowledge into its basic elements and studying the connections between them, and then create graphics in the form of networks to facilitate dealing with the required knowledge [10]. Some researchers believe that the mind mapping method is consistent with the constructivist theory which believes that the individual's learning is constructed, that learners build new knowledge upon the foundation of previous learning and the prior knowledge influences what new or modified knowledge an individual will construct from new learning experiences [11]. Peng in [12] considered it as an effective teaching strategy that considers students' thinking; it can be used to effectively summarize and organize information and to facilitate their memorizing and retaining them more [13]. Mind mapping strategy in the educational field has attracted the attention of several researchers who conducted diverse studies aiming to examine its impact on students' achievement.

Abuzzait and Abu Sneineh [14] conducted a study entitled "The impact of using mind maps strategy in teaching science on achievement and attitudes among elementary students towards Science". The researchers adopted a quasi-experimental approach and implemented a program based on a strategy of mental maps, an achievement test and trend towards science. The study sample consisted of (60) female students who were randomly divided into two groups: the experimental group and the control group. The results revealed that there was an effect of the mind mapping strategy on achievement and attitudes towards science in favor of the experimental group.

Bawaneh [15] conducted a study aimed to compare the effects of the Mind Maps Teaching Method and the Conventional Teaching Method on tenth graders' immediate achievement and retention of electric energy concepts in Bani Kenanah public schools in Jordan. The randomly selected sample was divided into two groups. One group was taught by using the Mind Maps Teaching Method $(n=54)$ and the other group was assigned to the Conventional Teaching Method $(\mathrm{n}=57)$. The researcher used a multiple-choice physics concept test and open-ended questions. The findings showed that the Mind Maps Teaching Method was more effective than the Conventional Teaching Method in immediate achievement and retention of electric energy concepts. And there was a significant difference for students' gender on immediate achievement but not on retention.

Katcha, et.al, [16] conducted a study entitled "Effects of mind-mapping instructional approach on senior secondary school biology students' achievement in evolution in Minna, Niger State". The researchers adopted a pretest-posttest control quasi-experimental design for the study. The randomly selected sample comprised of (105) students. The results showed that the group taught using MMIA (experimental group) performed better than the control group, which were the students taught with the conventional lecture method. The result also showed that there was no significant difference in the mean scores of male and female students taught using MMIA.

In 2015, a study was carried out to determine the effectiveness of mind mapping and concept mapping as learning tools on students' academic achievement in 
biology by Ogundele [17]. The researcher adopted a quasi-experimental pre-test and post-test. The sample comprised of (300) SS1 biology students randomly selected from five public secondary schools in Ijebu Ode Local Government Area of Ogun State. The results indicated that there was a significant difference between the mean pre-test and post-test scores of the students. It also showed that there was a significant difference among the mean values of the pre-test score as well as the mean values of the post-test scores of the students, implying that mind mapping and concept mapping are effective strategies for facilitating students' achievement in biology [17].

In Saudi Arabia, Jbeili [18] examined the impact of digital mind maps on science achievement among sixth-grade students. Quasi-experimental research was designed, and the sample consisted of (44) female students. The results revealed that using digital mind maps had a significant effect on students' science achievement. Based on the obtained results, it was concluded that the application of digital mind maps could improve the students' achievement.

Hourani [19] conducted a study aimed at investigating the effect of using mind maps on students' achievement in science. The study was applied in the Palestinian city of Qalqilya to the ninth- grade students. An achievement test in science and a scale of attitudes toward science were used. The results showed that there was a statistically significant difference in the mathematical mean for students' scores in favor of the experimental group.

Al-Zoubi [20] conducted a quasi-experimental study to investigate the effect of teaching science using mind mapping strategies and concept maps on memorizing physical concepts in the subject of electrical current among eighth-grade primary school students in Ramtha District. A study of the physical concepts test was used in the study. The results showed that there were statistically significant differences between the averages of the students' grades in the physical concepts test in favor of the mind mapping strategy compared to the concept maps strategy and the conventional method.

Baker [21] carried a semi-experimental study to investigate the effect of using E- mind mapping strategy in solving physical problems among tenth-grade students in the light of their learning styles. The study used the (VARK) learning styles scale and the test of solving physics problems. The findings showed that there were statistically significant differences in the performance of students with visual and multiple learning styles on the test of solving physics problems attributed to the teaching strategy and in favor of E- mind mapping strategy and a statistically significant effect attributed to the interaction between the teaching strategy and the learning style.

Wilson, Solas, and Dixon in [22] mentioned that employed an action research methodology approach. The study aimed at enhancing the teaching and learning experience in general education, particularly Environmental Science class for most Emirati English Language Learners (ELL) through using the mind mapping method. The results are based on a group of 60 students, showed that this method is quite useful in helping pupils summarize lengthy lessons and increase student engagement and communication amongst peers. In addition, this method further facilitates on-the-spot identification of misconceptions that students may have. The result also indicated that students were more responsive and motivated as they positively contribute to their learning environment.

In Malaysia, Masnaini [23] aimed to examine the effects of Cooperative Integrated Reading and Composition (CIRC) with mind mapping strategy on the achievement and motivation of 11th-grade Secondary students in Pekanbaru Indonesia regarding topics related to colloid. The study employed a pre-test/post-test quasi-experimental design. The findings indicated that the integration of cooperative learning strategies in reading and writing with a mind map had a positive impact on students' achievement and motivation. There was a significant difference in achievement between the treatment group with the infusion of learning reading and writing with a mind map and the control group with conventional teaching, whereas there were no significant differences in motivation between the treatment group and the control group.

It is noteworthy that some other studies have examined the impact of the E-mind mapping strategy on students' achievements on other subjects, but they have differed in terms of the size of the study sample. All these studies have followed the quasi-experimental research and record the same finding, that there was a significant impact of using the e-mind mapping strategy on improving students' performance, for example, in learning English vocabulary [24-25] and developing academic achievement and the attitude towards Learning English. Mohaidat in [26] examined the impact of E- mind maps on students' reading comprehension, while Mahasneh in [27] investigated the effects of electronic mind mapping on achievement and attitudes in an educational psychology course.

It is known that achievement is influenced by internal and external factors such as the learner himself or the teaching strategies. Actually, students differ in their learning styles [28]. Learning styles as a concept indicates how the learner receives knowledge, information, experience, and how he organizes it in his repository of knowledge [29]. Several learning styles have confirmed that everyone has his style to acquire knowledge assuming that the process of receiving, and processing information is inherent in the individual's personality and is reflected in all learned tasks [30]. Therefore, the idea of applying students' preferred learning styles in the teaching strategies has received considerable interest of educators because of its impact on improving the quality of education and raising the level of student's academic achievement [31]. 
Based on the foregoing, concerning the theoretical literature on mind mapping, and learning styles, this study came to investigate the effectiveness of the e-mind mapping strategy and learning styles on the achievement of tenth-grade students in Biology.

\subsection{Statement of the Problem}

Science contributes greatly to the progress and development of nations; hence, several efforts have been globally employed to improve science curricula and finding new and appropriate teaching methods meeting the demands of this era. Educational research has indicated that the use of mind maps improves achievement in science as the studies of [19-18], achievement in physics as mentioned [20-21], and achievement in biology [5].

Achievement is influenced by various factors, including the students' preferred learning style. [2] confirmed that $(75 \%)$ of the achievement depends on the students themselves. Despite the expansion in the use of technology in teaching in Jordan, there is a decline in the results of Jordanian students in (TIMSS) and (PISA) tests according to the report [1]. In addition to the scarcity of studies that dealt with the effectiveness of using mind mapping strategy in Jordan, hence, this study came to investigate the effectiveness of this new method of teaching and learning biology, taking into consideration students' favorite learning styles. The researcher attempted to answer the following question:

- Are there statistically significant differences at the level of significance $(\alpha=0.05)$ between the mean of the post-measurement of the performance of the tenth-grade students on the achievement test in biology according to the teaching strategy (E-mind mapping, the conventional method) and the learning styles (reading/writing, audio) and the interaction between them?

\subsection{The Importance of the Study}

A. Theoretical importance: This study is one of the few studies that examined the effect of the E-mind mapping strategy on students' achievement in biology in light of learning styles, so it is hoped that it will enrich the educational literature with its results. It is also a starting point for conducting similar studies on other samples and variables and benefited from the instruments and the results of this study when conducting future studies in this field.

B. Practical significance: It is hoped that the current study will provide knowledge that contributes to guiding teachers to make use of the E-mind mapping strategy. Educational leaders and specialists can also benefit from the study instruments and result in the field of training teachers to use the E-mind mapping strategy.

\subsection{Study Terms and Operational Definitions}

The study included the following terms:

- E-mind mapping: that the learner creates on a subject using computer programs that contain a set of instructions with some features such as editing, revising, printing, and sharing with others [33]. It is procedurally defined as the steps and procedures used in teaching and learning the unit of "taxonomy and Prokaryotes", to convert ideas and information into words, shapes, and images, via a computer using the mind mapping program (Mind Mapper 2017).

- Academic achievement: It is the extent of students' comprehension of what they have acquired through specific experiences in the studied curricula that are measured by the degree that students receive in the achievement tests prepared for that reason [34]. Operationally it is the mean for the responses of the participants on the unit "taxonomy and Prokaryotes". Learning style: it is the method the learner utilizes to acquire knowledge, information, and experiences and he uses to organize the acquired knowledge through recording, symbolizing and assimilating this information in his cognitive repository. Then he communicates and expresses the acquired knowledge in his [29]. Operationally, it is the student's preferred learning style determined by the participant's responses on the (VARK) scale.

\subsection{Study Limitations}

The study is limited to tenth-grade students enrolled in public schools in Al Koura Directorate of Education in the second semester of the academic year 2017/2018.

- The study is limited to the unit "taxonomy and Prokaryotes" from the biology book for the tenth grade, which was approved by the Ministry of Education for the academic year 2017/2018.

- The study is limited to using the Mind Mapper (Mind Mapper 2017) program.

- For the validity and reliability of the "taxonomy and Prokaryotes", Bloom's cognitive domains (recall, understanding, application, analysis) were used.

- The validity and reliability of the VARK scale in classifying students according to their learning styles.

\section{Methods}

\subsection{Study Population}

The study population comprised of (1382) tenth-grade students in public schools in Al Koura Directorate of Education in the Irbid Governorate in the second semester of $2017 / 2018$. The study population distributed over (42) 
tenth-grade classes in (15) schools for boys according to the statistics of the Department of Educational Statistics for the academic year 2017/2018.

\subsection{Study Sample}

The study purposeful sample consisted of (74) students in the tenth-grade, who were enrolled in a public school in Al Koura Education Directorate. The sample was randomly divided into two groups: (An experimental group) studied by using E- mind mapping strategy, and (a control group) studied using the conventional method.

\subsection{Study Instruments}

A. Preferred learning styles Scale: To determine the preferred learning styles of the participants, the (VARK) questionnaire was used after translating it into Arabic and introducing it to specialized arbitrators to ensure the correctness of the translation, the integrity of the linguistic structure of the items, the suitability of the items to what it measures, and their appropriateness to students' situations and levels in the Jordanian environment. Fleming model [29] was used to correct responses. To check the reliability of the scale, it was applied and re-applied to a survey sample consisting of (24) students. The coefficient of internal consistency was (0.87), and Test-Retest Reliability was $(0.81)$. The correlation coefficients for each style were calculated with the overall scale, where they were as follows: the visual style (0.77), the auditory style (0.68), and the reading / writing style (0.68), and kinetic style (0.82). Correlation coefficients were also calculated between the styles as shown in Table (1).

Table 1. Pearson correlation coefficients values for the relationship between the learning styles

\begin{tabular}{|c|c|c|c|}
\hline Relationship & Visual & Auditory & Reading/writing \\
\hline Visual & 0.60 & & \\
\hline Reading/writing & 0.65 & 0.52 & \\
\hline Kinetic & 0.75 & 0.70 & 0.65 \\
\hline
\end{tabular}

B. The achievement test: To measure achievement in the unit "Taxonomy and Prokaryotes", a multiple-choice test was built with four alternatives. The final form consisted of (35) items, distributed over the first three levels of the Bloom's Taxonomy: remember (9) items, understand (17) items, apply (7) items.

1. The validity of the achievement test: The content validity of the test was checked by presenting it to six professional arbitrators. They checked the appropriateness, comprehensiveness of the test items for the content of the educational subject, and the affiliation of the items to the subject it covered. The construct validity was also confirmed by applying it to the participants. The difficulty index and discrimination index for each item were measured with the test as overall, and Bloom Taxonomy levels to which it is affiliated. The internal construct validity was checked by measuring Pearson's correlation coefficients for the test with its Bloom classification levels on one hand, and the internal correlation of Bloom's taxonomy levels on the other hand, Where the values of the correlation coefficients with the test as a whole ranged between (0.69- 0.86). Pearson correlation coefficients were between (0.35-0.57).

2. The reliability of the achievement test: To verify the reliability of the test, the internal consistency coefficient of the test was measured and its value was (0.88), while the values of the internal consistency coefficients for the Bloom taxonomy levels (remember, understand and apply) ranged between $(0.44-0.84)$. The test-retest value was (0.78), while the values of the test-retest coefficients for Bloom's taxonomy levels (knowledge, comprehension, and application) ranged between $(0.84-0.92)$. These values are considered appropriate for approving the final application of the test on the study sample [35].

\section{Procedures}

Choosing a public school intentionally from Al Koura Educational Directorate to carry out the study on the tenth- grade students, and to determine the experimental and control group.

- Choosing the unit (taxonomy and Prokaryotes) from the biology book for the tenth grade (Part Two), analyze it, and defining the required goals.

- Reconstructing the unit sections "taxonomy and Prokaryotes" and organizing them according to the Emind maps strategy.

- The learning styles Scale were applied to the participants, and they were classified into two types (reading/writing and auditory).

- The pre-test achievement test was applied to the two groups (control and experimental).

- The educational unit was taught in the conventional method to the control group, and the experimental group was taught by applying the E-mind maps in the computer lab.

- The achievement test was applied after the experiment to the two groups (control and experimental); the papers were corrected, and the marked.

\section{Results and Discussion}

The study aimed to identify the effect of using E-mind 
mapping strategy and learning styles on the achievement of the tenth- grade students in biology by answering the main study question: "Are there statistically significant differences at the level of significance $(\alpha=0.05)$ between the mean of the post-measurement of the performance of the tenth-grade students on the achievement test in biology according to the teaching strategy (E-mind mapping, the conventional method) and the learning styles (reading / writing, audio) and the interaction between them ?" The participants' prevalent learning styles were gauged. Two of these prevailing learning styles out of the four learning styles according to (VARK) were more prevalent which are reading / writing and auditory style, then mean and standard deviations were calculated for the pre and post-test of students' performance on the achievement test in biology according to the teaching strategy and their learning style, as indicated in Table (2).

Table (2) shows that there is an apparent difference between the two arithmetic means of the post-test for the performance of the tenth-grade students on the achievement test in the subject of biology due to the different levels of teaching strategy and learning style. To check the difference between them, the researchers used the Two-way analysis of variance between the arithmetic means of the post-test of the performance of the tenth-grade students on the achievement test in the subject of biology according to the teaching strategy and their learning style after neutralizing the effect of the pre-test of students' performance on the achievement test, as shown in Table (3).

Table (3) illustrated that there is a statistically significant difference at the level of significance $(\alpha=0.05)$ between the two arithmetic means for the post-test of the performance of the participants on the achievement test in biology attributed to the teaching strategy. The adjusted two-post arithmetic means for the performance of tenth-grade students on the achievement test in biology and its standard errors were calculated according to the teaching strategy and the learning style, as well as the interaction between them to determine which of the two study groups was most significant. The adjusted two-dimensional arithmetic mean was calculated for the performance of the tenth-grade students, as illustrated in Table (4).

Table 2. Mean and SD for pre and post-test of the respondent on the achievement test in biology according to the teaching strategy and their learning style

\begin{tabular}{|c|c|c|c|c|c|c|}
\hline \multirow{2}{*}{ Teaching strategy } & \multirow{2}{*}{ Learning } & \multirow{2}{*}{ No. } & \multicolumn{2}{|c|}{ Pre-test } & \multicolumn{2}{|c|}{ Post-test } \\
\hline & & & Mean & SD & Mean & $\mathrm{SD}$ \\
\hline \multirow{3}{*}{ Conventional } & auditory & 11 & 10.09 & 3.08 & 18.18 & 2.75 \\
\hline & reading/writing & 13 & 11.62 & 4.27 & 17.62 & 4.11 \\
\hline & Overall & 24 & 10.92 & 3.78 & 17.88 & 3.49 \\
\hline \multirow{3}{*}{ E-mind mapping } & auditory & 17 & 10.12 & 3.74 & 23.59 & 3.68 \\
\hline & reading/writing & 33 & 9.79 & 3.30 & 25.12 & 3.79 \\
\hline & Overall & 50 & 9.90 & 3.42 & 24.60 & 3.79 \\
\hline \multirow{2}{*}{ Overall } & auditory & 28 & 10.11 & 3.44 & 21.46 & 4.25 \\
\hline & reading/writing & 46 & 10.30 & 3.64 & 23.00 & 5.14 \\
\hline
\end{tabular}

Table 3. Two-way analysis of variance between the arithmetic means of the post-test of the performance of the tenth-grade students on the achievement test in biology according to the teaching strategy and learning style after neutralizing the effect of the pre-test of students' performance on the achievement test

\begin{tabular}{|c|c|c|c|c|c|c|}
\hline Source of variance & SS & $\mathrm{Df}$ & $\mathrm{S}$ & $\mathrm{F}$ & $\mathrm{SE}$ & Effect size \\
\hline Pre-test & 5.47 & 1 & 5.47 & 0.40 & 0.53 & $0.57 \%$ \\
\hline Learning style & 2.95 & 1 & 2.95 & 0.21 & 0.64 & $0.31 \%$ \\
\hline Teaching strategy & 653.82 & 1 & 653.82 & $47.54^{*}$ & 0.00 & $40.80 \%$ \\
\hline Teaching strategy*learning style & 19.32 & 1 & 19.32 & 1.41 & 0.24 & $2.00 \%$ \\
\hline Error & 948.88 & 69 & 13.75 & & & \\
\hline Overall & 1716.01 & 73 & & & & \\
\hline
\end{tabular}

* Statistically significant at the significance level $(\alpha=0.05)$. 
Table 4. The adjusted arithmetic means for post-test of Tenth-Grade students' performance on the achievement test in Biology and its standard errors according to teaching strategy, learning style, and interaction between them

\begin{tabular}{|c|c|c|}
\hline \multicolumn{3}{|c|}{ Post-test } \\
\hline Teaching strategy & Adjusted mean & SE \\
\hline Conventional & 17.85 & 0.76 \\
\hline E-mind mapping & 24.38 & 0.55 \\
\hline
\end{tabular}

Table (4) shows that the primary difference was in favor of the participants of the experimental group who were taught utilizing the E-mind mapping strategy compared to their counterparts in the control group who were taught by applying the conventional teaching method. The value of the effect size of the teaching strategy which is $(40.80 \%)$ indicates the effectiveness of employing the E- mind mapping strategy in improving the achievement of tenth-grade students in Biology according to the standard of Abu Hatab and Cohen mentioned in [36]. The researchers interpreted this result by the fact that the participants of the experimental group learned through a teaching method that focuses on scientific concepts and the link between them, while the control group learned by using the conventional method that focuses on memorizing and recalling information without understanding it. The reason may also be attributed to the fact that E- mind maps link material information with graphics, colors, and sensory things, which evokes students' minds to learn since learning becomes better when both the left and right sides of the brain are employed [4]. This is what employing E-mental maps in learning can achieve as they integrate written information with graphics and symbols. Besides, the use of mind maps harmonizes with the constructivist theory that depicts knowledge as an activity that is constructed and formed by the learner. All of this may be contributed to the appearance of such a difference between the arithmetical means of the two groups.

These results are consistent with the results of [6]; [15-23], which indicated the effectiveness of the mind mapping strategy and with the studies of [24-27] who pointed out that E-mind mapping, has contributed in levitation the academic achievement of students. Table (3) also shows that there is no statistically significant difference at the level of significance $(\alpha=0.05)$ between the two arithmetic means of the post-test of the performance of the participants on the achievement test in biology course to the learning style or the interaction between the teaching strategy and their learning style.

Given that there is a statistically significant difference to the achievement test due to the teaching strategy, it required analysis on the levels of Bloom's classification (remember, understand, and apply) included in it. Therefore, the mean and the standard deviations for the pre and post-test of the responses on the achievement test were calculated according to the teaching strategy and the learning style, as indicated in Table (5).

Table 5. Mean and SD for pre and post-test of the responses at Bloom's taxonomy levels in the achievement test according to the teaching strategy and learning style

\begin{tabular}{|c|c|c|c|c|c|c|c|}
\hline \multirow{2}{*}{$\begin{array}{c}\text { Test cognitive } \\
\text { levels }\end{array}$} & \multirow{2}{*}{ Teaching strategy } & \multirow{2}{*}{ Learning style } & \multirow{2}{*}{ No. } & \multicolumn{2}{|c|}{ Pre-test } & \multicolumn{2}{|c|}{ Post-test } \\
\hline & & & & mean & SD & mean & $\mathrm{SD}$ \\
\hline \multirow{8}{*}{ Remember } & \multirow{3}{*}{ Conventional } & auditory & 11 & 2.27 & 1.56 & 3.09 & 0.54 \\
\hline & & Reading/writing & 13 & 3.00 & 1.22 & 3.15 & 0.80 \\
\hline & & overall & 24 & 2.67 & 1.40 & 3.13 & 0.68 \\
\hline & \multirow{3}{*}{ E-mind mapping } & auditory & 17 & 2.71 & 1.40 & 5.35 & 1.37 \\
\hline & & Reading/writing & 33 & 2.52 & 1.48 & 5.39 & 1.41 \\
\hline & & overall & 50 & 2.58 & 1.44 & 5.38 & 1.38 \\
\hline & \multirow{2}{*}{ Overall } & auditory & 28 & 2.54 & 1.45 & 4.46 & 1.57 \\
\hline & & Reading/writing & 46 & 2.65 & 1.42 & 4.76 & 1.62 \\
\hline \multirow{8}{*}{ Understand } & \multirow{3}{*}{ Conventional } & auditory & 11 & 5.27 & 1.79 & 9.73 & 1.79 \\
\hline & & Reading/writing & 13 & 6.46 & 2.85 & 9.15 & 3.00 \\
\hline & & overall & 24 & 5.92 & 2.45 & 9.42 & 2.48 \\
\hline & \multirow{3}{*}{ E-mind mapping } & auditory & 17 & 4.82 & 1.94 & 11.88 & 1.80 \\
\hline & & Reading/writing & 33 & 4.73 & 2.11 & 12.52 & 2.00 \\
\hline & & overall & 50 & 4.76 & 2.04 & 12.30 & 1.94 \\
\hline & \multirow{2}{*}{ Overall } & auditory & 28 & 5.00 & 1.87 & 11.04 & 2.06 \\
\hline & & Reading/writing & 46 & 5.22 & 2.44 & 11.57 & 2.75 \\
\hline \multirow{8}{*}{ Apply } & \multirow{3}{*}{ Conventional } & auditory & 11 & 2.55 & 1.29 & 4.73 & 1.56 \\
\hline & & Reading/writing & 13 & 2.15 & 1.82 & 4.77 & 1.36 \\
\hline & & overall & 24 & 2.33 & 1.58 & 4.75 & 1.42 \\
\hline & \multirow{3}{*}{ E-mind mapping } & auditory & 17 & 2.59 & 1.77 & 5.12 & 1.45 \\
\hline & & Reading/writing & 33 & 2.55 & 1.46 & 5.82 & 1.33 \\
\hline & & overall & 50 & 2.56 & 1.55 & 5.58 & 1.40 \\
\hline & \multirow{2}{*}{ Overall } & auditory & 28 & 2.57 & 1.57 & 4.96 & 1.48 \\
\hline & & Reading/writing & 46 & 2.43 & 1.56 & 5.52 & 1.41 \\
\hline
\end{tabular}


Table 6. Results of Bartlett's test of sphericity for Pearson correlation coefficients for the post-test relationship of sample responses at Bloom's Taxonomy levels according to teaching strategy and learning style

\begin{tabular}{|c|c|c|}
\hline $\begin{array}{c}\text { Relationship according } \\
\text { to teaching strategy and } \\
\text { learning style }\end{array}$ & $\begin{array}{c}\text { Remembering } \\
\text { post-test }\end{array}$ & $\begin{array}{c}\text { Understanding } \\
\text { post-test }\end{array}$ \\
\hline $\begin{array}{c}\text { Post-understanding } \\
\text { measurement }\end{array}$ & 0.33 & 0.33 \\
\hline $\begin{array}{c}\text { Post applying } \\
\text { measurement }\end{array}$ & 0.48 & SR \\
\hline \multicolumn{2}{|c|}{ Bartlett's test of sphericity } \\
\hline$\chi^{2 *}$ & DF & 0.00 \\
\hline 51.94 & 5.00 & $0.05)$. \\
\hline
\end{tabular}

Table (5) shows that there is an apparent difference between the two means of the post-test of the responses of the respondents at the levels of Bloom's Taxonomy (remembering, understanding, and applying) resulting from the different teaching strategies and the learning style. To confirm the significance of the difference, Pearson's correlation coefficients of the post-test were calculated between the levels, followed by Bartlett's test of sphericity according to the teaching strategy, the pattern of learning and the interaction between them, as indicated in Table (6).

By examining Table (6), we realize that there is a statistically significant relationship at the level of significance $(\alpha=0.05)$ between post-test at Bloom Taxonomy levels (remembering, understanding, and applying) according to the teaching strategy and the learning style. Therefore, it was necessary to carry out the Two-way analysis of variance between the mean of the post-test of the overall responses according to the teaching strategy and their learning style as shown in Table (7).

Table (7) shows that there is no statistically significant effect at the significance level $(\alpha=0.05)$ of the learning style or the interaction of the teaching strategy with students' learning style and that there is a statistically significant effect at the significance level $(\alpha=0.05)$ of the teaching strategy. To determine which level of Bloom's Taxonomy was significant, Two-way analysis of variance was carried out between the mean for the post-test of responses on the levels of Bloom's taxonomy (remembering, understanding, and applying) individually according to the teaching strategy and learning style as indicated in Table (8).

Table 7. The MANOVA between the mean of the post-test of the overall responses according to the teaching strategy and their learning style

\begin{tabular}{|c|c|c|c|c|c|c|c|}
\hline \multirow{2}{*}{ Effect } & \multicolumn{2}{|c|}{ MANOVA } & \multirow{2}{*}{$\begin{array}{l}\text { f value } \\
\text { overall }\end{array}$} & \multicolumn{2}{|c|}{$\mathrm{df}$} & \multirow{2}{*}{ SD } & \multirow{2}{*}{ Effect size } \\
\hline & type & value & & hypothesis & Error & & \\
\hline Pre-test & Wilks' Lambda & 0.96 & 0.89 & 3 & 67 & 0.45 & 0.0383 \\
\hline Teaching strategy & Hotelling's Trace & 0.98 & $21.83^{*}$ & 3 & 67 & 0.00 & 0.4943 \\
\hline Learning style & Hotelling's Trace & 0.02 & 0.48 & 3 & 67 & 0.70 & 0.0210 \\
\hline $\begin{array}{l}\text { Learning style*teaching } \\
\text { strategy }\end{array}$ & Wilks' Lambda & 0.97 & 0.71 & 3 & 67 & 0.55 & 0.0308 \\
\hline
\end{tabular}

Table 8. Two-way analysis of variance between the mean of the post-test of the responses on the levels of Bloom's taxonomy (remembering, understanding and applying) individually according to the teaching strategy and learning style

\begin{tabular}{|c|c|c|c|c|c|c|c|}
\hline $\begin{array}{l}\text { Dependent } \\
\text { variable }\end{array}$ & Source of variance & SS & DF & MS & $\mathrm{F}$ & SR & Effect size \\
\hline \multirow{6}{*}{$\begin{array}{c}\text { Remembering } \\
\text { post-test }\end{array}$} & Pre-test & 0.49 & 1 & 0.49 & 0.32 & 0.57 & $0.47 \%$ \\
\hline & Teaching strategy & 79.24 & 1 & 79.24 & $52.63^{*}$ & 0.00 & $43.27 \%$ \\
\hline & Learning style & 0.02 & 1 & 0.02 & 0.01 & 0.90 & $0.02 \%$ \\
\hline & Teaching strategy*learning style & 0.00 & 1 & 0.00 & 0.00 & 0.97 & $0.00 \%$ \\
\hline & error & 103.88 & 69 & 1.51 & & & \\
\hline & overall & 186.86 & 73 & & & & \\
\hline \multirow{6}{*}{$\begin{array}{l}\text { Understanding } \\
\text { post-test }\end{array}$} & Pre-test & 6.17 & 1 & 6.17 & 1.36 & 0.25 & $1.93 \%$ \\
\hline & Teaching strategy & 123.21 & 1 & 123.21 & $27.10^{*}$ & 0.00 & $28.20 \%$ \\
\hline & Learning style & 0.01 & 1 & 0.01 & 0.00 & 0.97 & $0.00 \%$ \\
\hline & Teaching strategy*learning style & 7.10 & 1 & 7.10 & 1.56 & 0.22 & $2.21 \%$ \\
\hline & error & 313.72 & 69 & 4.55 & & & \\
\hline & overall & 461.15 & 73 & & & & \\
\hline \multirow{6}{*}{$\begin{array}{l}\text { Applying } \\
\text { post-test }\end{array}$} & Pre-test & 0.57 & 1 & 0.57 & 0.29 & 0.59 & $0.41 \%$ \\
\hline & Teaching strategy & 7.45 & 1 & 7.45 & 3.77 & 0.06 & $5.17 \%$ \\
\hline & Learning style & 2.31 & 1 & 2.31 & 1.17 & 0.28 & $1.66 \%$ \\
\hline & Teaching strategy*learning style & 1.43 & 1 & 1.43 & 0.72 & 0.40 & $1.04 \%$ \\
\hline & error & 136.60 & 69 & 1.98 & & & \\
\hline & overall & 153.85 & 73 & & & & \\
\hline
\end{tabular}

* Statistically significant at the significance level $(\alpha=0.05)$. 
By studying Table (8), we can conclude that there is a statistically significant difference at the significance level $(\alpha=0.05)$ between the two means for the post-test for the responses on the Bloom Taxonomy levels (remembering and understanding) attributed to the teaching strategy. To determine which of the two study groups has a significant difference, the two adjusted means were calculated for responses on the levels of Bloom's taxonomy, and the two standard errors for both of them was calculated separately according to the teaching strategy as shown in Table (9).

Table 9. The adjusted means for the post-test for the responses on Bloom's Taxonomy Levels and their standard errors for each according to teaching strategy

\begin{tabular}{|c|c|c|c|}
\hline $\begin{array}{c}\text { Dependent } \\
\text { variable }\end{array}$ & $\begin{array}{c}\text { Teaching } \\
\text { strategy }\end{array}$ & Adjusted mean & SE \\
\hline \multirow{2}{*}{$\begin{array}{c}\text { Rememberin } \\
\text { g post-test }\end{array}$} & conventional & 3.11 & 0.25 \\
\cline { 2 - 4 } & $\begin{array}{c}\text { E-mind } \\
\text { mapping }\end{array}$ & 5.38 & 0.18 \\
\hline \multirow{2}{*}{$\begin{array}{c}\text { Understandi } \\
\text { ng post-test }\end{array}$} & $\begin{array}{c}\text { E-mind } \\
\text { mapping }\end{array}$ & 12.22 & 0.44 \\
\hline
\end{tabular}

Table (9) indicates that the significant difference was in favor of the participants of the experimental group, where the effect size of the teaching strategy based on E-mind mapping - as indicated in Table (12) - on the level of remembering is above average (43.27\%), and on the level of understanding is less than average (28.20\%) according to the standard of (Cohen) [36]. This result may be attributed to the employment of E- mind mapping strategy which helps in speeding up learning, organizing ideas, recalling information and integrating the learner into the educational process to reach the highest levels of concentration [4]. Employing E- mind maps provide an opportunity to introduce the educational content in an integrated way, as the different forms of scientific knowledge included in the content are linked using graphics, symbols and illustrations, and this would help students to store information and link the new knowledge with previous one [13]. Thus, meaningful learning was achieved, enabling the participants of the experimental group to remember and understand the information, and with a statistically significant difference compared to the control group.

Table (8) illustrates that there is no statistically significant difference at the level of significance $(\alpha=0.05)$ between the two means for the post-test of the responses on Bloom's Taxonomy levels (understanding, remembering, application) due to the learning style or the interaction between the teaching strategy and the learning style. This indicates that the achievement in biology course does not differ according to the preferred learning style according to the participants' responses, whether using the E-mind mapping strategy or the conventional method. This result differs from the results of Baker [21], which indicated that the ability to solve physical problems is due to the learning style, and the interaction between the learning style and the teaching strategy. This may be attributed to the differences between the taught subject and the sample. The study of [21] was applied to students of the tenth grade in physics, while the current study was applied to tenth-grade students in a biology course.

\section{Recommendations}

- Employing an E-mind mapping strategy in teaching science and biology for different educational stages.

- Studying the effect of the E-mind mapping strategy on other variables such as learning retention and gender.

\section{REFERENCES}

[1] The National Center for Human Resources Development. Jordan's level of performance in the International Mathematics and Science Study 2015, Amman, Jordan, 2016.

[2] Zaytoun, A.. Science teaching methods. I 7. Amman: Al-Shorouq for Publishing and Distribution, Jordan 2013.

[3] Zaytoun, A. Structural theory and science teaching strategies. Amman: Al-Shorouq for Publishing and Distribution, Jordan .2007.

[4] Buzan, T, and Buzan, B. (2007) Mind Map Book. 4th edition, Jarir Bookstore, Kingdom of Saudi Arabia.

[5] Wakad, H. The effectiveness of using mental maps to obtain some topics of biology course for large first-graders first graders in Makkah Al-Mukarramah, unpublished master's thesis, College of Education, Umm Al-Qura University, Makkah Al-Mukarramah, Kingdom of Saudi Arabia. 2009.

[6] Abu Saidi, A, and Balushi, S. Methods of teaching science, concepts, and practical applications. Amman: Al-Masirah House for Publishing, Distribution, and Printing, Jordan, 2009.

[7] Holzman, S. Thinking maps: Strategy-based learning for English language learners. Annual Administrator Conference 13th Closing the Achievement Gap for Education learner student, Sonoma country office of Education, California Department of Education, 2004.

[8] Rifai, N. Step by step maps. Kuwait: consulting and training skills, 2006.

[9] Nong, B., Pham, T., \& Tran, T. Integrate the digital mind mapping into teaching and learning psychology. Teacher Training Component- ICT. Vietnam, 2009.

[10] Drake, k., \& Long, D. Rebecca's in the dark: A comparative study of problem-based learning and direct instruction /experiential learning in two 4th-grade classrooms. Journal of Elementary Science Education, 21(1), 1-16, 2009.

[11] Harkirat, S., Makarimi, K., \& Anderson, R. Constructivistvisual mind map teaching approach and the quality of students' cognitive structures. Journal of Science Education 
and Technology,20 (2),186-200, 2010.

[12] Peng, S. The Effect of Combining Mind Map and Electronic Picture-Books on Fourth-Graders' reading comprehension Ability and Reading Motivation. (Unpublished Master's thesis). Taiwan: National Pingtung University of Education, 2011.

[13] Tucker, J. M., Armstrong, G. R., \& Massad, V. J. Profiling the mind map user: A descriptive appraisal. Journal of Instructional Pedagogies, 2 (4), 1-13, 2010.

[14] Abuzzait, Y., Abu Sneineh, O. The Impact of Using Mind Maps Strategy in Teaching Science on Achievement and Attitudes among Elementary Students towards Science. Journal of Studies in the Humanities and Social Sciences vol (3). No(03) (26). ISBN:978-9957-67-204-1 - ISSN (ISSN-L):2617-9857, 2020.

[15] Bawaneh, Ali. The effectiveness of Using Mind Mapping on Tenth Grade Students' Immediate Achievement and Retention of Electric Energy Concepts. Journal of Turkish Science Education. 16(1):123-138 March 2019. DOI 10.12973/tused.10270a, 2019.

[16] [16] KATCHA, M. A.1; ORJ, A.B.C.1; FRANCISCA, U. EBELE1; ZAINAB ABUBAKAR1; \& BABAGANA MOHAMMED (2018). effects of mind-mapping instructional approach on senior secondary school biology students' achievement in evolution in Minna, niger state, NIGERIA. Journal of Science, Technology, Mathematics and Education (JOSTMED), 14(2), March 2018

[17] Olusegun, E. (2015). Mind mapping and concept mapping as effective learning tools in biology education. Conference: Interdisciplinary Conference of UCC-TASUED, At University of Cape Coast, Ghana, Volume: 1,2015.

[18] Jbeili, I. (2013). The Impact of Digital Mind Maps on Science Achievement among Sixth Grade Students in Saudi Arabia. Procedia - Social and Behavioral Sciences 1031078 - 1087, 2013.

[19] Hourani, H. The effect of using the mental mapping strategy on the achievement of the ninth students in science and their attitudes towards science in government schools in the city of Qalqilya. Unpublished Master Thesis, An-Najah National University, Nablus, Palestine, 2011.

[20] Zoubi, F. The effect of teaching science with the strategies of mental maps and concept maps on retaining the physical concepts of eighth-grade students: a comparative study. Unpublished Master Thesis, Yarmouk University, Jordan, 2015 .

[21] Baker, H. The effect of computerized mind mapping strategy on solving the physical problems of 10th-grade students in the light of their learning styles. Journal of Educational Sciences, 43 (3), 1841-1859, 2016.

[22] Wilson, K; Solas, E, and Dixon, N. A preliminary study on the use of mind mapping as a visual learning strategy in general education science classes for Arabic speakers in the
United Arab Emirates. Journal of the Scholarship of Teaching and Learning, Vol. 16, No. 1, pp.31-52. DOI: 10.14434/josotl.v16i1.19181, February 2016.

[23] Masnaini, J. Copriad, J and Osman, K. Cooperative integrated reading and composition (CIRC) with mind mapping strategy and its effects on chemistry achievement and motivation. Asia-Pacific Forum on Science Learning and Teaching, Volume 19, Issue 1, Article 2, p.1,2018.

[24] Shdaifat, S., Al-Abed Al-Haq, F, and Al-Jamal, D. The Impact of an E-mind Mapping Strategy on Improving Basic Stage Students' English Vocabulary. Jordan Journal of Modern Languages and Literature Vol.11, No. 3, pp 385-402,2019.

[25] Aljaser, A. The Effectiveness of Electronic Mind Maps in Developing Academic Achievement and the Attitude towards Learning English among Primary School Students. International Education Studies 10(12):80 - DOI: 10.5539/ies.v10n12p80. November 2017.

[26] Mohaidat, M. (2018). The Impact of Electronic Mind Maps on Students' Reading Comprehension. English Language Teaching 11(4):32. DOI: 10.5539/elt.v11n4p32, March 2018.

[27] Mahasneh, A. The effect of using electronic Mind Mapping on Achievement and Attitudes in an introduction to educational Psychology Course. The new educational review. DOI: 10.15804/tner.2017.47.1.23, 2017.

[28] Hawk, T., and Shah, A. Using Learning Style Instruments to Enhance Student Learning, Decision Sciences. Journal of Innovative Education, 5(1): 1-19, 2007.

[29] Fleming, N. \& Bonwell, C. How do I learn best: A student guide to improved learning. Colorado: Green Mountain Falls, 2002.

[30] [30] Zayat, F (2004). The psychology of learning between a relational and cognitive perspective. 2nd floor, Cairo: University Publishing House, Egypt.

[31] Ouelette, R. Rouuellette@umuc.edu. Learning Styles in Adult Education. Retrieved April 10, 2018, retrieved. http://www.learningstyles.com.

[32] Zaytoun, H. E-learning. Riyadh: The Sawlaty House for Education, Kingdom of Saudi Arabia, 2005.

[33] Lokani, A, and Jamal, A. A glossary of educational terms defined in curricula and teaching methods. 3rd floor. Cairo: World of Books for Publishing and Distribution, Egypt, 2003.

[34] Odeh, A. Measurement and evaluation in the teaching process. Irbid: Dar Al-Amal for Publishing and Distribution, 2010.

[35] Sherbiny, Z. Statistics and experimental design in psychological, educational, and social research. The Anglo-Egyptian Library, 2007. 